General report topic 3 / Rapport général thème 3

\title{
HYDRAULICAL AND HYDROGEOLOGICAL TESTING TO DETERMINE THE PERMEABILITY OF THE PORES OR TRANSMISSIVITY OF THE FRACTURES
}

\section{ESSAIS HYDRAULIQUES ET HYDROGEOLOGIQUES EN VUE DE LA DETERMINATION DE LA PERMEABILITE DE PORES OU DES FRACTURES DE LA TRANSMISSIVITE}

\section{MANFREDINI G.}

\section{Introduction}

The field of investigation covered by Session 3 is very broad; it regards in situ permeability measurements in soil and rock using widely differing techniques according to the different nature of the soils, the depth to investigate, and according to the particular problems of the case in question (fig. 1).

A significant aspect of permeability measurements is that only very rarely are laboratory tests representative of actual field conditions. It is well-know that the values obtained in situ differ by several orders of magnitude from the laboratory results, because of the presence in natural soils of "structural features". In the case of rock massifs fissures and joints are present (accounting for most of the water flow), and in the case of soils, very fine lithologic or grainsize variations and thin layering are a characteristic trait. It is therefore indispensable to carry out in situ tests to characterize the permeability. The very structural characteristics make it generally necessary to consider permeability as a "tensor". In most cases the planning and carrying out of in situ tests has to take this aspect into account. The variety of testing equipment and methodologies vary

Papers dealing mainly with:

Soil mechanics problems $\bullet \bullet \bullet \bullet \bullet \bullet \bullet \bullet \bullet$
Rock mechanics problems $\bullet \bullet \bullet \bullet \bullet \bullet \bullet \bullet \bullet \bullet$

Depthinvolved by the test:

\begin{tabular}{|c|c|}
\hline $0 \div 10$ & $\bullet \bullet \bullet \bullet \bullet \bullet \bullet \bullet$ \\
\hline $10 \div 200$ & $\bullet \bullet \bullet \bullet \bullet \bullet \bullet \bullet \bullet \bullet \bullet \bullet \bullet$ \\
\hline $200 \div 2000$ & $\bullet \bullet \bullet \bullet$ \\
\hline
\end{tabular}

Type of equipment used to determine permeability:

Packer test of different types

Pumping wells, open hole tests

Tracers

Self boring or pushing-in instruments

Large scale test

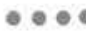

Flowmeter

\section{-}

Geophysical methods
Fig. 1. Distribution of papers according to nature of soil, depth involved, equipment used. thoroughly as a function of the depth of investigation which may be on the order of a metre when only the permeability of the superficial soil layer is to be determined (e.g. for agricultural purposes), or of thousands of metres when the permeability of formations to be used as waste disposals is to be known, or of formations from which fluid is to be drawn, or finally, when the stability of broad subsident areas is to be examined.

Usual investigations for civil engineering problems rarely exceed a depth of $150-200$ metres; problems related to permeability measurements at greater depths generally lie out side the day-to-day engineering experience and must therefore be dealt with with great caution.

Permeability site investigations are performed in different types of soils and rocks; the planning and interpretation of these investigations, furthermore quite often involve, as demonstrated in the papers presented, not only knowledge in the fields of Soil Mechanics and Rock Mechanics, but also in other domains.

An interesting aspect which is emphasized by the papers presented at this session is that, permeability measurements are certainly amongst the different investigations, those whose planning and interpretation require a rather accurate geological knowledge of the area under examination. In some cases, where the permeability of whole geological formations are required in order to correctly interpret the data, an exhaustive geological knowledge of the region is imperative.

In recent years there has been much progress in the area of in situ permeability measurements, especially in the development of new testing equipment, and this very topic has been discussed in special sessions at recent International Conferences. The interest aroused by the topic, and the advancement in knowledge that has been achieved is fully witnessed by the 28 papers presented at this Session, produced by 11 European and 5 non-European countries.

It is interesting to note that in spite of developments in the in situ permeability measurement techniques, there still are many uncertainties as to the meaningfulness of measurements obtained through the different methods in relation to the specific problems under examination. Indeed, it must be recalled that even today it is not uncommon to find a coefficient of variation of the permeability on the order of $200 \%$.

The papers presented at Session 3 of this Symposium may be broadly divided into 5 groups of topics dealing mainly with:

In situ determinations for characterizing a "regional" permeability;

Modern "in borehole" testing techniques, or meaningful upgradin of routine techniques in the field of civil engineering;

*ENEL - Italian State Electricity Board, Dept. of Construction Rome (Italy) 
Measurements of permeability at great depths, or in relation to non-traditional problems;

Theoretical and general analyses with a view to more correctly interpreting permeability tests;

Case histories, and special in situ tests.

It is evident that each paper does not strictly focus on only one of the topics of the outline, but the latter can be used for ease of exposition. Most of the papers however deal with the second topic thus emphasizing the progress that has at present been achieved in this sector. In the review, special attention is paid to the comparison between results of different in situ testing methods, and between these and the results obtained from full-scale in situ tests or from back-analyses. This comparison will certainly lead to a better understanding of the field tests.

\section{In situ determinations for characterizing a "regional" permeability}

Quite often, for large-scale engineering problems, it is necessary to know the permeability of formations extending out over kilometres; a typical problem is the construction of artificial reservoirs; furthermore, permeability coupled with deformability govern the subsidence of large areas (Miyabe, 1969; Poland, 1969; Croce, 1973; Colombo, 1973) which is related to the lowering of the water table caused by the pumping of fluids from deep wells.

Large scale permeability is moreover important for taking into account changes in the hydrogeological conditions brought about by the urbanization of large areas (Louis, 1981).

In relation to "regional permeability, particular importance has always been attached - as regards carbonatic rocks - to karst phenomena. The presence of this, may cause perméability to rise by various orders of magnitude.

The "large-cale" characterization of permeability has developed essentially by trying to attache (at least to a regional extent) general validity to permeability tests carried out in some typical geological formations.

A recent and interesting review of many in situ permeability tests in differing types of rock formations is given by Brace (1980).

The different permeability values referred to vary within a range of 20 orders of magnitude, and at the same investigation depth and for the same rock formation, within the range of 4 orders of magnitude.

Besides the classical in situ tests, that in any case would have to be carried out in large numbers and over extensive areas in order to be meaningful on the regional scale, in situ permeability may be calculated by analysing various large-scale phenomena whose development depends on permeability. It is possible to consider such phenomena as fullscale "in situ tests", carried out on large volumes of rock or soil, but on the other hand, this approach has the drawback that the phenomena under investigation (delays between fluid injection and seismic response, flow-rate increases following seismic events, examination of hydrothermal phenomena, etc.) are generally extremely complex, and their functional relation with permeability not easy to solve. Even if the values obtained are unlikely to be used for most civil engineering works, they may prove to be useful for characterizing the permeability of deeper soils.

An interesting application of the analyses of large-scale phenomena for solving typical civil engineering problems has been provided by Uriel Romero and Aoiz (1981), who developed a method for determining the permeability of the terrain affected by large-scale excavation near the coast, on the basis of the damping effects with which the oscillation of the tide is transmitted througn the porous media.

A recent example of regional characterization of the British non-carbonatic mudrocks in hydrogeological terms has been given by Tellam and Lloyd (1981) on the basis of a wide variety of in situ and laboratory tests, by utilizing many uncollected data, or data scattered throughout the geological, hydrogeological, soil mechanics, mining and agricultural literatures.

Also the paper presented at this Session by $K R A P P$, which is very interesting from a methodological standpoint, refers to the characterization of geological formations for problems related to the civil engineering activity. This paper examines and evaluates a series of data referring to the permeability of Paleozoic and Mesozoic rock in the western Renish mountain areas of Germany. The evaluation was based essentially on a critical re-examination of numerous in situ borehole permeability tests, on observations of water inflow into tunnels and of water tables in monitored holes and wells in the area. Further information on permeability has been obtained by means of tracers (especially in karstic areas), and finally, by utilizing hydrogeological balance data following run-off during dry season in small catchment areas.

For a regional characterization of the superficial layer of rock formations (where most of the flow occurs) the dominant factor for the permeability is the "effective open crack volume".

On the basis of this parameter (which may vary from $0.1 \%$ in the case of phyllitic rocks, up to $10-15 \%$ for karstic limestones and up to $50 \%$ for travertine) a useful classification scheme is presented which could be used in permeability maps.

The paper stresses that in evaluating the "regional" characteristic of geological formations, it is usually insufficient to utilize a single type of test, but rather, all the possible elements available for a synthetic judgement should be taken into consideration.

GANGOPADHYAY prents a practical case where the permeability of a large area was to be defined for the construction of a hydroelectric plant in a highly karstified area. The investigation followed the lines mentioned in the foregoing, that is: a) survey of the piezometric levels and of the relating pressure gradients; b) extensive surveys using chemical and radioactive tracers in order to determine short- and long- distance interrelations due to karst phenomena; c) hydrological balance for the different areas. These investigations positively showed karstic interconnections in the different areas of the plant.

A different approach to permeability characterization of geological formations is provided by Alessandrello and Lemoine's paper who point out, on the basis of an extensive series of experimental results, the possibility of correlating resistivity (measured by means of geophysical methods) with permeability in the case of some sandygravelly alluvial deposits in France. The need to know the pore water resistivity to have better correlations and thus use geophysical data for making forecasts is pointed out, and the influence of clayey soils on the global resistivity of the formations is also discussed. The collection of similar data for the alluvial formations of other countries could prove to be greatly useful, thus allowing to amplify and verify the validity of such correlations for application purposes, and possibly to reach more general semi-empirical relations between the different parameters. 
Table 1

Technique

Principles of Technique

Permeability

tests

\section{Packer}

tests

(Lugeon test)

Falling head

tests

Constant head

tests

\section{Pumping}

Pumping
test

.

Water is pumped out from or injected into a borehole in the ground

A section of a borehole is closed with packers at top and bottom and water is pumped in under pressure; water losses are recorded. Alternatively a single packer is used to test the part of the borehole below it.

A test section in a borehole is isolated by casing. The borehole is filled with water and the rate of fall of waterlevel is observed.

A test section in a borehole is isolated by casing. The borehole is filled with water; water is added to the borehole to keep the water level constant.

Water is pumped out of a borehole, observations are made of waterlevel in the hole and in nearby holes.
Data Obtained

Permeability

Permeability of the investigated rock mass expressed in standard units of permeability or in lugeon units.

Permeability of the test section.

Permeability of the test section.

Permeability of the investigated rock or soil mass.
Application

Ground masses of different types.

Used in rock mass of relatively low permeability.

Mostly in soils of low permeability.

Mostly in rocks of mode rate or high permeability.

\section{In-situ Testing - Permeability Testing}

(after "Report of the IAEG Commission on site Investigations, 1981).

\section{Comment}

A precise knowledge of the natural groundwater level is required.

The value of the results will be related to the frequency and aperture of the joint systems in relation to the size of the borehole.
If sufficient observation holes are made, some information on the anisotropy of the groundmass may be deduced.
Used in rock and soil mass.

\section{Modern "in borehole" testing rechniques or meaningful upgrading of routine techniques in civil engineering}

The in situ permeability of soils and rock formations is generally determined, for civil engineering purposes, by the application of a hydraulic pressure head difference between the water in the borehole and that in the surrounding ground, and to measure the resulting flow. A number of analyses and tests were developed since the last century for different geometrical and hydrogeological conditions, which take into account the transient or permanent flow in order to obtain the mean permeability of a "porous medium".

The testing techniques and the interpretation theories were later "extended" or "adjusted" to non-granular media, such as fractured rock masses and very low permeability soils. soils.

In the following table (after the Report of the IAEG Commission on 'Site Investigations', 1981) the in situ permeability tests routinely used are outlied*.

Besides these widely used types, innovations have come to add with the aim of obtaining indications also for low-

\footnotetext{
* Field test relating to permeability scheduled to be published as "Suggested Methods" by ISRM are the following (see Franklin, 1979).

- Permeability / transmissivity (5 methods)

- Flow velocity logs

- Flow velocity - tracer dilution

- Flow paths using tracers (4 methods)
}

permeability soils by running water tests in piezometers, for obtaining continuous permeability logs with depth (flowmeters, tracers, dipole probes) or for measuring local transmissivity of fissures in rock masses (harmonic probe).

A detailed description of routine in situ permeability tests and a presentation of the different methods for interpreting results as well as technological details involved, is found in "Ground water Manual" edited by U.S.B.R. (1977). Useful suggestions are also presented in many recent Site Investigation Manuals or Standards.

An extensive in situ investigation making use of most of the available routine methods, with some innovations, has been carried out for the Ok Tedi Project (Papua New Guinea) by Sutcliffe and Mostyn. A description is given of the advantages and liabilities for each type of test carried out (constant head test, falling head test, packer test), the costs involved are computed. The considerable advantages in terms of time and cost offered by the wireline pneumatic packer system against the mechanical or hydraulic packers are described.

Also the paper presented by Foyo Marcos deals with borehole permeability tests. Referring to experience gained with dam foundation investigations in Spain, he suggests that by producing hydraulic fracturing, information about the mechanical characteristics of the rock mass may be inferred. It is however known that the pressure at which hydraulic fracturing phenomena initiate is essentially dependent upon the horizontal stresses $\sigma_{\mathrm{H}} \max$ and $\sigma_{\mathrm{H}} \min$, form the tensile strength of the rock mass, and from preexisting pore pressures (Haimson, 1978 and at this Symposium); only a more detailed analysis (with the measure of 
the shut in pressure and of the secondary breakdown pressure) would, ideally, allow an evaluation of the tensile strength of the rock mass.

It is often pointed out that the interpretation of packer permeability tests may be strongly biased when some particular aspects are not taken into account, namely, actual pore pressure in the surrounding soil, water losses through the packer, and head losses in the drop pipe; indeed, some head loss may occur (especially in the case of high flow rates) also at the perforated pipe section and inlet section (Moore and Balbis, 1979). Much effort has been put into improving the reliability of such tests; Maini et al. (1972) suggest to use a directional triple cell packer; to use transducers to measure the effective pressure in the test cell; to use two testing chambers for source-sink tests, etc. Along the same research lines, an experimental programme has been carried out by Pearson and Money (1977) with the main objective of distinguishing between anomalies due to test method faults (such as packer leakage, head loss in the equipment, etc.) and non-equilibrium effects due to the hydraulic properties of the rock mass, which may depend on the duration of the test and on the sequence of the operations. An extensive revision of the theoretical and practical background of this standard test has also been carried out by the German Geological Survey and at the Technical University of Aachen (Heitfeld and Krapp, 1981)

The paper by Blinde et al. presents useful suggestions to improve the reliability of the test, amongst which is the recording of the water head inside the cell and of the flow throughout the test. To better interpret the results, optical bore-hole soundings and dye tracings were performed. A comparison was made with the experimental grouting in a test area with bentonite-cement suspensions. Subsequent excavations showed that the grout had propagated around the hole between 1.50 and $2.00 \mathrm{~m}$.

As in many other cases reported in the literature (Capozza, 1977) geophysical methods (and in particular "p" wave velocity) proved to be appropriate for inspecting the effectiveness of the grouting.

The paper by Haimson focuses on the need to carry out in a coordinated manner, and virtually with one set of tools, measurements of the state of fracturing, of the state of stress and of permeability inside each bore-hole. Indeed, it is well-known that, even if the parameter "fracturing" is not univocally related to permeability, in principal the latter does depend on the nature, and on the opening of the "hydraulically active" discontinuities, that are in communication with each other to form a single "network". The state of stress greatly influences permeability (by reducing space openings) as discussed in other papers presented at this session. It should therefore be measured where possible jointly with the measurement of permeability.

The proposed equipment consists essentially of a straddle packer appropriately instrumented with pressure transducers, by means of which hydraulic fracturing is achieved, and an "impression packer" which is used in the fracturing zone, so as to check the real orientation of the fractures which develop, and the original fissuring of the rock mass. Before fracturing (or even afterwards) the same equipment can be used to measure the permeability according to the "Pulse test" method (that is, by applying a pressure pulse on the order of $0.5-1 \mathrm{MPa}$ and by recording the decay characteristics of the pulse), or by the more classical measurement methods such as the "constant head technique".

The full orientation of the entire core (in order to get a global view of the discontinuities arrangement) is obtained by means of a television camera or by occasional impression packer tests in the critical stretches.

Daw and Scott's paper examines permeability tests appropriate for obtaining information about the possibility of large water inflow during the excavation of deep underground works: the possibility of foreseeing such accidents may lead to localised preliminary reclamation measures.

In these conditions the simpler tests do not provide ade quate results especially because of the limited area of influence of the test. The "drill stem test", that has been used in the oil industry for some time now, consists essentially of educting water from an aquifer over a specified flow period by utilizing the volume of the empty drill stem, and in recording the recovery of pressure following the shutting off of the flow. In this manner, volumes of rock masses from tens to hundreds of metres around the hole may be affected. By plotting appropriate diagrams, the transmissivity of the rock mass is determined. In strong aquifers at shallow depths, however, the drill stem fills up so rapidly that the effective flow rate during the test becomes uncertain. The solution worked out to overcome this difficulty includes the use of submersible pumps capable of operating down to depths of $200 \mathrm{~m}$.

Continuous monitoring of the pressure with appropriate transducers, the control of the effective complete expansion of the packers by monitoring the compressor used for inflation, further improves the utilization of such data.

A very interesting development for recognizing hydraulically active fractures is described in Crosnier et alii's paper. The paper discusses the utilization of the "harmonic probe" (already used in the laboratory tests, and for in situ tests at great depths) in geotechnical investigations. The basic principle of the equipment consists in exciting the fissures of the rock mass filled with fluid, by a sinusoidal signal consisting of a pulsing flow, and in recording the corresponding pressures as output signals.

The complex relationship between the output signal (in pressure) and the output signal (flow), which is a function of the frequency of the signal, characterizes the tested fissuring system. The fissuring parameters are identified by comparing them with a set of characteristic signals obtained through numerical modelling, which may keep account of the forces of inertia, of those due to viscosity and of the compressibility of the rock and fluid. Such equipment allows permeabilities of the order of even $10^{-12} \mathrm{~m} / \mathrm{s}$ to be measured.

The laboratory calibration of the prototype, carried out on a physical plexiglass model proved a substantial agreement between the physical and the mathematical models. It is pointed out that the use in practice of this equipment will entail the need to study different interpretational models according to the geological and geotechnical characteristics of each site to be investigated.

The permeability of rock masses is in general influenced by the state of stress, and for this reason the state of flow and the state of stress in the rock mass cannot be evaluated separately; the two problems must be considered strongly coupled.

The relationship between permeability and state of stress has been investigated by different Authors (Morgenstern and Guther, 1972; Jouanna, 1972; Bernaix, 1969; Rosengren and Jaeger, 1967). It appears that permeability can vary by more than one order of magnitude for the modifications of the state of stress normally induced by engineering structures. This is particularly important in evaluating dam behaviour (Manfredini et al., 1975). As to the type of 
functional relationship between permeability and stress tensor, a simplified hypothesis is to assume that the permeability of the rock mass is always isotropic and that its value depends only on the mean stress. On this assumption different relationships were proposed by Morgenstern and Guther (1972) and by Louis and Perrot (1972).

Laboratory tests were carried out by Rosengren and Jaeger (1967) on the geomechanical models of fractured rocks obtained by thermal disgregation of a marble; the results showed that the permeability in a given direction does not depend on the stress acting along that same direction, but only on the stresses acting on a plane normal to it.

A more adequate model of the stress-dependent permeability in which such behaviour is taken into account can be worked out by assuming that the principal directions of the stress and permeability tensor coincide and that each principal permeability is independently influenced by the two principal stresses in the other principal directions (Manfredini et al., 1975).

The validity of such constitutive laws can be checked only by in situ tests on significant volumes or, where possible, on the basis of the behaviour of life-size structures. A useful contribution to this study is provided by the paper presented by Carlsson and Olsson, where an in situ test is described which consisted in measuring the permeability of a significant volume of a rock mass $\left(\simeq 6 \mathrm{~m}^{3}\right)$ at variable states of stress induced in the rock mass by a series of hydraulic jacks acting on steel bars. The permeability tests consisted essentially of water injection tests by means of double packers.

It must be mentioned that this type of test has the advantage, as compared with tests on isolated blocks, of avoiding loosening in the sample and therefore a fictitious increase in the permeability.

The tests showed that at increasing vertical loads there were decreasing horizontal permeabilities, but, as a general trend, an increase in conductivity through steeply dipping fractures.

The latter result does not appear to be immediately understandable as the increase in vertical stress should also give rise to an increase in horizontal stress and therefore to a closing of the vertical fissures. As can be expected, the rise in the hydraulic test pressure, by reducing the effective pressures, causes an increase in permeability.

The measurement of the dilution over time of tracers introduced into the holes, sometimes provides useful indications as to the permeability of the soils and especially about the type of flow of water inside the aquifer. It can furthermore provide indications on the effectiveness of grouting measures or, in some cases, give indications on the trend of seepage in earth dams. Three papers of the Session were devoted to this topic. Radioactive tracers for geophydrological investigations are discussed in detail in Gautier and Rousselin's paper. Bromium 82 and indium $113 \mathrm{~m}$ were used as markers. The half-life of the former is 36 hours (it thus allows to carry out tests lasting 5-6 days), and of the latter it is about 100 minutes, which means that tests lasting one day may be carried out and that the same test or other tests may be repeated on the same place. Both have the advantage of being lowly toxic.

Some useful technological measures (for example a directional probe) make it easy to determine the direction of the horizontal component of the water motion.

The use of the radioactive tracers is discussed also in the paper presented by Huller, et al.; measurements of the water flow according to the dilution of the tracer over time and measurements of the soil permeability on the basis of the vertical displacements of the tracer inside the hole were carried out.

The paper also discusses the use of radioactive tracers for controlling a sealing wall built with self-hardening suspensions, and for studying the geometry of a landslide.

In Malkki and Wihuri's paper a similar problem is discussed. To determine the permeability of fluvioglacial deposits, colourimetric or electrolytic tracers were used instead of the radioactive ones, so as to avoid drawbacks due to toxicity. Dilution is measured either by means of a light source and photocells, or, where electrolytes are used, by measuring the conductivity of the medium between two electrodes. In order to obtain greater reliability, an experimental calibration was used to turn dilution velocity into actual velocity.

The flowmeter allows a recording of permeability values with depth for soils having permeabilities in the range of $10^{-4}-10^{-7} \mathrm{~m} / \mathrm{s}$. This technique has the advantage of being very rapid and inexpensive.

The paper presented by Bruzzi et al., discusses the results obtained by using such equipment in an alluvial plain. The testing techniques are described. The results obtained under conditions of natural flow, or "dynamic" flow following an artificial rise in level are compared with Lefranc's tests carried out in the same holes.

Notwithstanding the uncertainties and approximation which characterize, in general, such determinations, it was verified that the agreement between the two sets of measurements deviated by only $10 \%$.

Other comparisons were made with laboratory tests on undisturbed samples, or on the basis of empirical correlations based on grain-size analyses.

Emphasis is given on the importance of a very careful installation of the perforated casing and of the filter between casing and soil to get reliable information about the permeability.

The determination of permeability of fine soils (silts and clays) was carried out almost exclusively in the laboratory up to 15 years ago, by means of time-settlement curves in oedometer tests. The forecasting of the settlements over time for engineering structures, has always therefore proven to be rather uncertain due to the fact that laboratory tests cannot adequatly represent the structural conditions of the in situ material (presence of thin more permeable intercalations in soft clays, the presence of joints and fissures in the overconsolidated clays, etc.). In order to improve the knowledge about the actual in situ permeability of silty. clayey soils, different research lines are being pursued, most of which are complementary.

An exhaustive review on this topic was presented by Jamiolkowski et al, (1979). A possible line is that of taking and testing samples of such a size as to include also the "structure" of the clayey deposits being examined; samples of Fiumicino soft clays having a diameter of $0.49 \mathrm{~m}$ and height $\cong 0.20 \mathrm{~m}$, were tested in œdometric conditions (Burghignoli and Calabresi, 1977); a second possibility is that of trying to get a more detailed as possible representation, at least in quantitative terms, of the structural characteristics (sandy intercalations, etc.) of the deposit by using the piezometric probe or the piezocone continuous test, which is highly sensitive to the detection of layering (even if slight) having different permeability inside a clay deposit. A third way is that of directly evaluating the consolidation coefficient starting from the curve of pore pressure dissipation generated in situ by stress variations. This may be attained for example with the same 
piezocone, stopping the penetration and allowing pore pressure dissipation; some drawbacks, however, consist in high remoulding and disturbance in the structure of the deposit around the point, and in the geometric conditions, not duly represented by the theory of cavity expansion.

A very promising tool from this standpoint is the Self Boring Pressuremeter (Clarke et al., 1979) that minimizes distrubance to the soil and is capable of inducing undrained stresses in the soil at a prefixed strain value, and to measure. subsequent pore pressure and the dissipation of these with time.

The cylindrical geometry allows a simple interpretation of the results.

A different approach for improving the reliability of the forecasts regarding the behaviour over time of the settlements of structures, starts from the consideration that it is usually possible to estimate to a close approximation the compressibility characteristics of the material (as is shown by the fact that the estimation of final settlements of engineering structures proves in general to be quite reliable), and therefore it may be sufficient to improve the reliability of the permeability measurement to obtain a better estimation of the consolidation coefficient. Three papers presented at this Session have followed this approach.

Regarding the direct in situ measurement of permeability in very fine soils by means of piezometers, a rather exten- sive bibliography is already available (Gibson, 1970; Bjerrum et al., 1972; Wilkinson, 1968; Wilkes, 1974; Massarsch, 1978; Mieussens and Ducasse, 1977).

In general, the piezometers to be used for measuring permeability can be installed in boreholes or directly placed inside the ground. In both cases it is necessary that drilling operations or the pushing in of the piezometer should not destroy the soil "structure"; moreoever, in the former case, the effective geometry of the sand filter into which the piezometer is placed (difficult to be known in detail) may considerably affect results ; in the latter case the pushing of the piezometer may lead to the remoulding of the soil (up to 3 to 5 times the diameter of the piezo. meter) and also to hydraulic fracturing if it is pushed in very rapidly; furthermore, the piezometer filter may get clogged with clayey material.

The paper by Tavenas et al. described a very promising tool that should eliminate most of the above-mentioned drawbacks.

The equipment proposed is a self-boring permeameter which is introduced at depth inside the soil in a similar way as the self-boring pressuremeter (Baguelin et al., 1974). In this way the effects of the pushing or the unknown geometry of the filter are eliminated.

Another innovation is the replacing of porous filter with a perforated metal lamina, whose holes are closed by a rubber membrane pressed against them during the penetration of
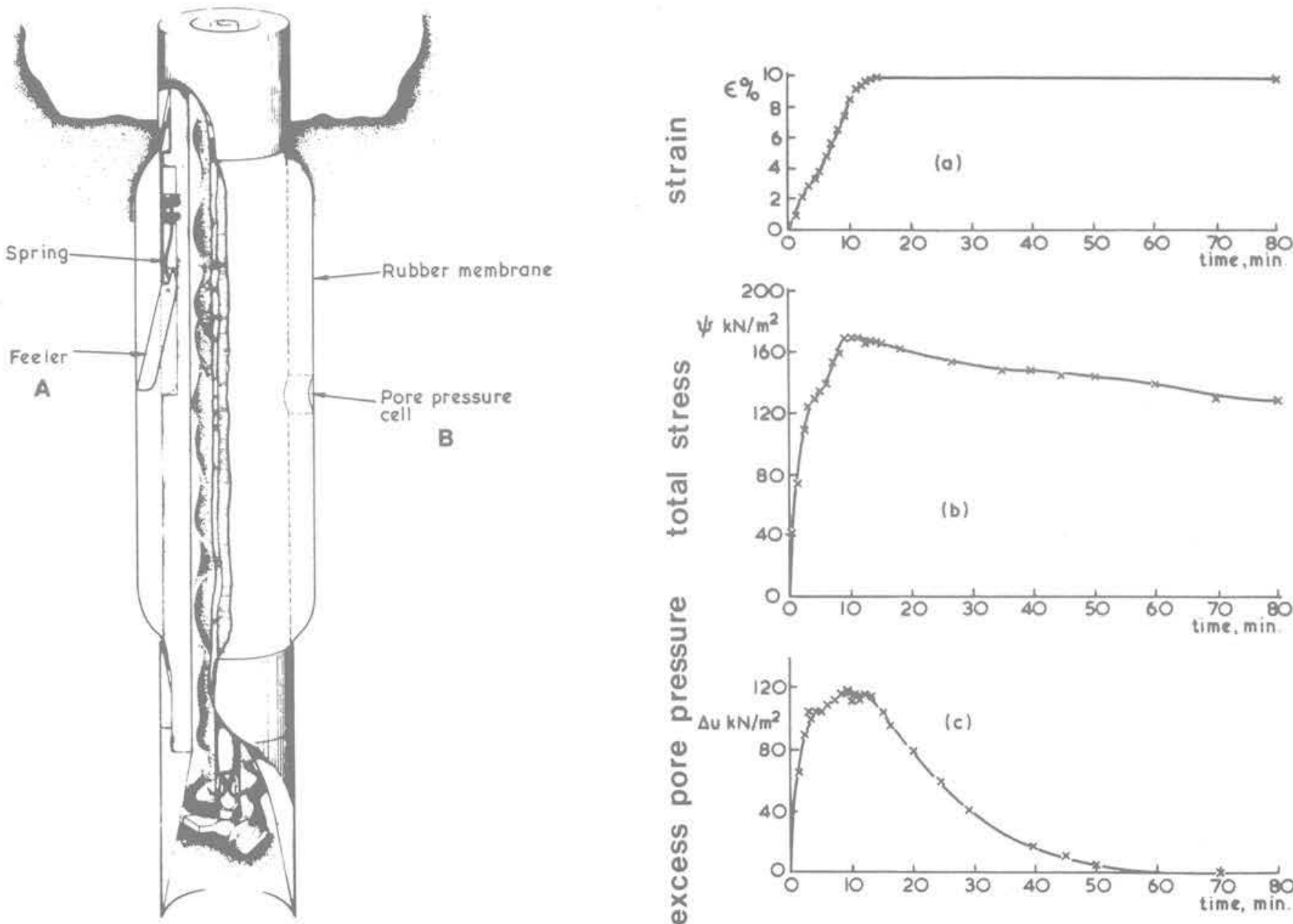

Fig. 2. The Cambridge self boring pressuremeter ; holding test (after Clarke et al., 1979). 
the tool. Inevitably, some remoulding due to the sliding of the tool against the soil still does occur, but reduced in extent. As regards the different modes of carrying out, the paper discusses their advantages and disadvantages; the variable head test (which is very easy to carry out) does however entail effective stress variations during the test and thus some errors in measuring the permeability which is difficult to evaluate; it furthermore refers to a rather limited soil volume,

As regards the constant head test, it is possible to keep account of the swelling of the material and thus define the steady flow and as a consequence the permeability of the soil; the volume involved by the test is substantially larger, but the testing equipment used so far is extremely complex and inadequate for routine testing.

The Authors suggest a very simplified equipment for carrying out constant head tests which are reasonably reliable and accurate. Comparisons are made between values obtained in situ with this equipment and the laboratory values for different soils. Interesting comparisons have also been made with the determinations obtained by introducing the permeameter without the self-boring device. The remoulding effect of the structure of the deposit is in the latter case quite evident.

For determining the permeability of a weathered and fissured clay layer, Lafleur and Giroux have develop a "reaming permeameter" which was to allow the cleaning of the walls of the hole (thus avoiding that the fissures might be filled with material); the possibility of carrying out measurements practically throughout the length of the hole; the possibility of measuring permeability values differing greatly among each other (even at a $10^{5}$ ratio) according to the presence or not of open fissures in the clay. The equipment used, which is introduced into an already bored guide hole, consists of a cutting reamer, two inflatable packers and an internal injection cell; it is introduced into the ground by means of hydraulic jacks. The permeability determinations were carried out at variable loads for the sake of simplicity in spite of the uncertainties linked to the interpretation of such measures. The hydraulic and the inflation pressures of the packer are proportioned so as to avoid hydraulic fracturing phenomena, yielding of the soil near the packer, and water leakage through them.

It must be naturally borne in mind that in such a weathered clays, the opening of fissures and thus permeability may have large seasonal variation. In case they are located above the water table, during the permeability test there may also be some swelling of the clay and closing of the fractures which considerably complicate the interpretation of test results.

The more correct way for determining the effective improvement in knowledge that can be attained by measuring permeability in situ instead of utilizing the classical laboratory tests, is the back analysis of the behaviour of structures (or better, a comparison between design forecasts and real behaviour of structures) as regards the settlementtime behaviour.

An interesting paper by Mieussens is devoted to this topic: during permeability tests the increase in effective stresses (for negative head changes) or the decrease of effective stresses (for positive head changes) are small. The results of permeability obtained may then be considered as referring to the soil in the preconsolidated state.

For the calculation it is assumed that the value of $c_{v}$ should not vary within the two soil domains (which are respectively the normally consolidated and the overconsolidated soils), and that the ratio of the two corres- ponding values $\left(c_{v s} / c_{v}\right)$ is equal to the reciprocal ratio of the compressibility indices. The findings of the in situ permeability tests obtained by means of the "Perméamètre Autoforeur", applied in two practical cases, yielded $\mathrm{c}_{\mathrm{v}}$ values which were much closer to those obtained by the back analysis than the laboratory results, but still not completely satisfactory (about 4.5-2 times greater than the actual values). Furthermore, the permeability values obtained in situ can be essentially referred to the horizontal permeability, whilst in the examined consolidation process it is mainly the vertical permeability which is involved, and this means a probably larger discrepancy between field tests and actual behaviour.

As an example, and to give an idea of the global usefulness of these determinations, the following fig. 3 (after Jamiolkowski et al., 1979) summarizes the results obtained by an extensive field and laboratory investigation carried out at Porto Tolle (Italy) for the construction of a thermo-electric plant. The findings are compared with a back analyses of trial embankments with or without vertical drains (which means involving mainly vertical or horizontal in situ permeability respectively).

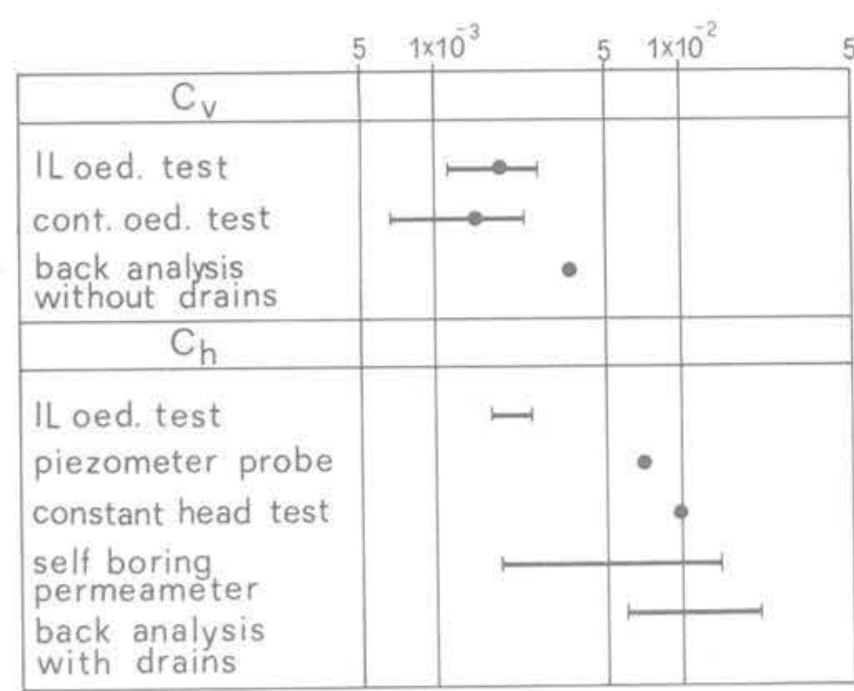

Fig. 3. Comparison between laboratory and in-situ $c_{y}$ and $c_{h}$ values at Porto Tolle (Italy) ; (data after Jamiolkowsk et al., 1979).

A look at the data shows that, first of all the different in situ tests for determining the horizontal permeability, or the horizontal consolidation coefficient $c_{h}$ (piezometer probe dissipation test, constant head permeability test and selfboring permeameter tests) provided comparable values; such values were higher than those obtained in the laboratory, but lower than those inferred from a back analyses of the development of settlement over time; moreover, as one might expect, the largest differences between the actual behaviour and the laboratory tests were found for the horizontal consolidation coefficient, that in some cases is most important (for example for an accurate design of the vertical drains).

The existing discrepancies are probably due to the different scale of the probe and of the macrostructure of the soil.

The Delft Soil Mechanics Laboratory has recently deve. loped an electrical porosity probe capable of measuring the porosity of saturated sands below water tables. This determination may be advantageously used for properly reconstructing, in the laboratory, sand samples with the same field density, thus obtaining reliable permeability 
values for homogeneous sand deposits (for the same objective the nuclear density probe, developed by the same laboratory, combined with a CPT test may be used). Given the formal analogy between the laws governing hydraulic and electric fields, a probe similar to that used for measuring resistivity was built for measuring soil permeability (dipole hydraulic probe). (Riestsema and Viergever, 1979). The article presented by De Leeuw and Silence, discusses this equipment. The probe, which has a diameter of $36 \mathrm{~mm}$, consists of four porous filters; through the first of these water is pressed into the soil; by a second filter at the other end water is sucked out by means of a reciprocating pump with a constant but adjustable rate of discharge. The potential difference between two other intermediate filters is measured with a differential pressure gauge. It can be shown that, unlike what one might think, this equipment measures essentially horizontal permeability. Vertical permeability may also be evaluated, once one knows the horizontal value, by placing two parallel probes, spaced $0.5 \mathrm{~m}$, which can measure the potential difference produced by adopting different schemes of water inflow and discharge.

It is very likely that, as occurs with piezometers pushed into the ground, there may be a certain disturbance in the soil around the dipole probe, due to packing of sand, or also due to localized failure in individual sand grains. Numerical verifications carried out with the SEEP programme have shown that, due to the type of measurements and of the type of materials generally investigated with this test, this distrubance does not give rise to large influences on the measured permeability value.

\section{Measuring permeability at high depths}

It is only in recent years that the permeability of soils and of rocks, situated at great depths, has become more and more important. The fields of application which need this knowledge are geothermal problems, production problems related to oil-fields, in-situ coal gasification, nuclear waste disposals, and also problems related to earthquake mechanics.

The reduction in frequency and opening of fissures with depth, and the corresponding decrease in permeability is reported by a large number of Authors. This decrease, for the first $100 \mathrm{~m}$, is generally very sharp and is found in almost all permeability tests and grouting measures involving rock foundations in dams (Snow, 1968; Davis and Turk, 1964 ; Bonaldi et al., 1983).

A recent review on the distribution of permeability at great depths for different rocks was made by Brace (1980). In general, there still does appear to be a decrease in permeability with depth, but the diversity of the rocks examined, and quite likely also the different testing methods used do not help in finding a general defined trend (fig. 4).

Some interesting overall indications on the presence of hydraulically active fissures even at great depths are provided by the results of a study on the structural and groundwater conditions in about 20 mines located in the Canadian Shield (Raven and Gale, 1977, also reported, by Witherspoon and Gale, 1977) fig. 5. In examining the data it must be borne in mind (as pointed out by the Authors), that the mining activities at different levels may mutually affect the water conditions and that ventilation can reduce seepage, which can be noticed in the walls.

The recent problem of the disposal of nuclear waste at grat depths (generally below $500 \mathrm{~m}$ ) in low-permeability soils has furthered knowledge in this fields.

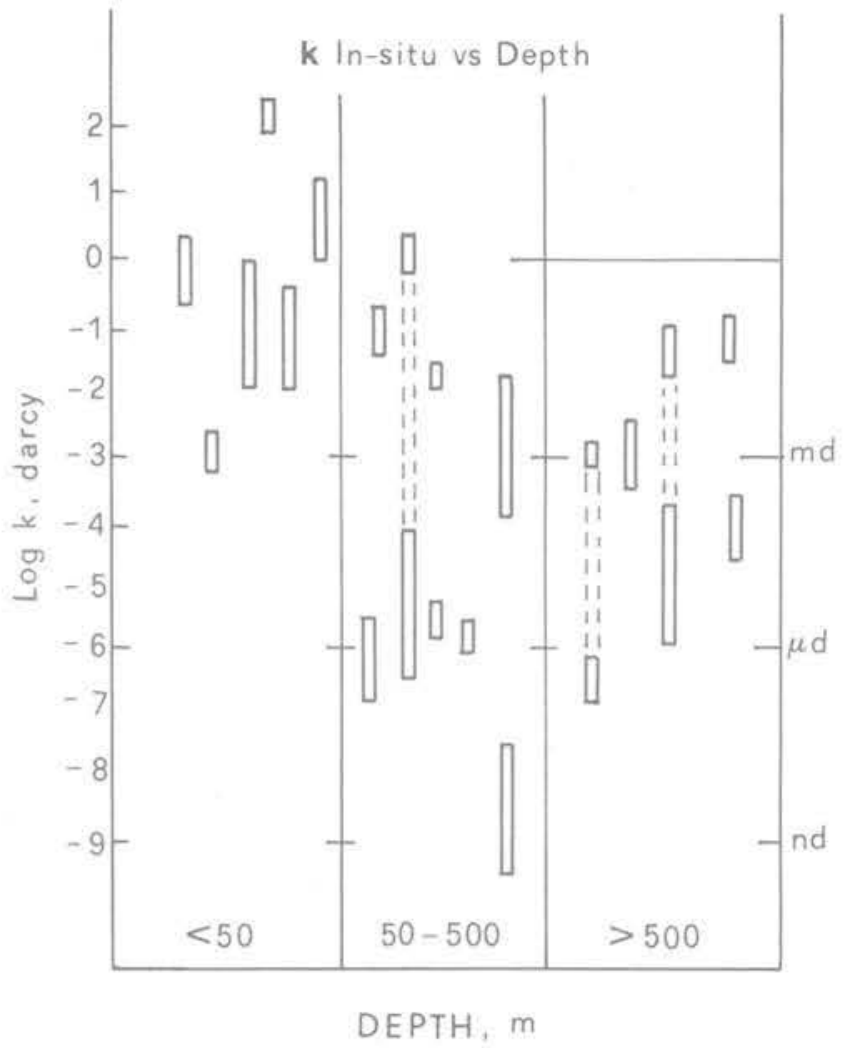

Fig. 4. In situ permeability values at different depth reviewed by Brace (after Brace, 1980),

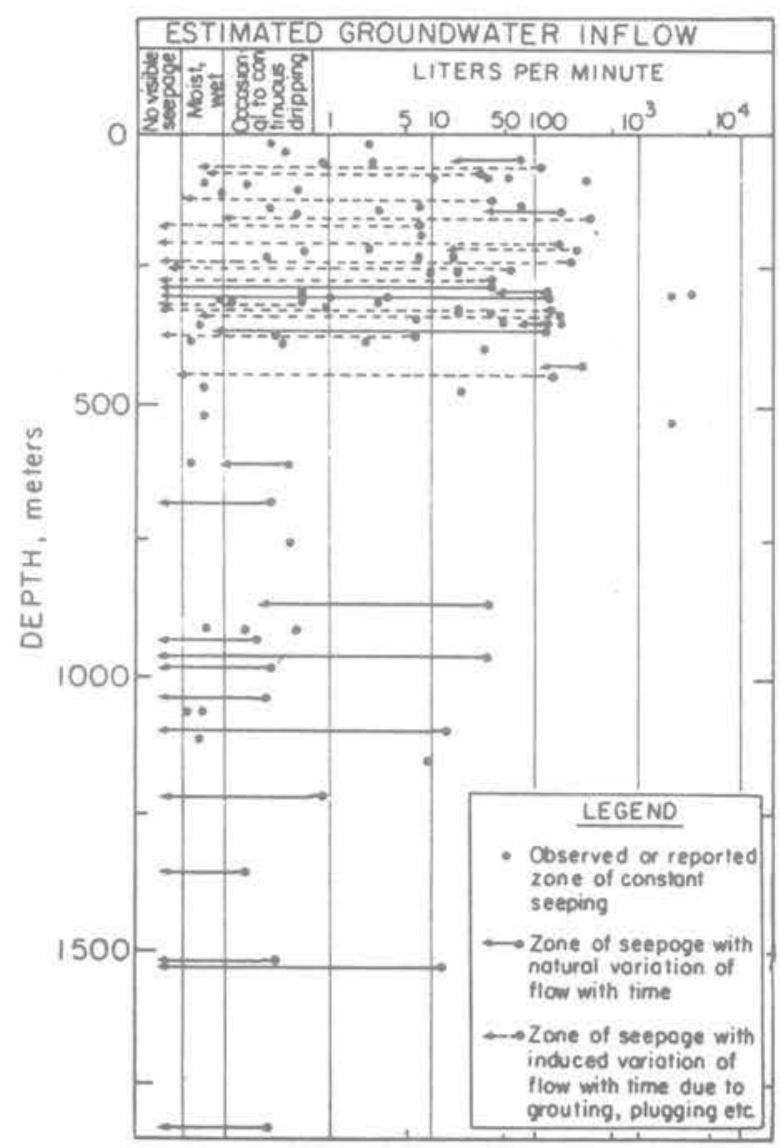

Fig. 5. Variation of groundwater inflows as a function of depth in selected underground mines (after Raven and Gale, 1977). 
Most of the investigations related to the examination of possible sites for waste disposal involve the determination of fracturing and of rock permeability, as the most likely way of transport of the radionuclides in the biosphere is via the water flow through the fissures in the rocks. The water flow in the rock mass around a waste disposal is essentially controlled by the heat which develops in the waste itself; the complex phenomena governing the water flow and heat transport (variations in the fluid viscosity or state variation of the fluid, variations in fissure openings or opening of new fissures due to thermal stresses etc.) are to be taken into account when dealing with these problems.

Three papers presented at this Session refer on special projects that are currently underway for clarifying some of these problems.

The first of these is the "Stripa Project", sponsored by seven countries, which examines the rock mass inside which lies an abandoned mine in Sweden; a second project exa. mines the characteristics of the granite and the gabbro plutons present in the Canadian Shield.

The paper by Witherspoon and Gale refer about a detailed site investigation focusing on the characterization of permeability in the Stripa granit massif; the programme consists of a detailed reconstruction of fracturing, tests in boreholes, and a large-scale permeability test along a stretch of drift which was appropriately equipped.

The injection tests in the boreholes showed, in spite of some scatter, a general trend of decreasing permeability with depth. Extremely interesting results have been obtained from a large-scale permeability test in a drift $5 \mathrm{mx}$ $5 \mathrm{~m} \times 33 \mathrm{~m}$ at el. 338 . Water inflow was measured as the net moisture pickup of the ventilation system in the drift, and water pressure was measured in isolated stretches in several boreholes departing from the drift. Water flow and pressures were monitored during 11 months. The findings of the various tests carried out at different temperatures of the ventilation air, provided practically constant values of hydraulic conductivity of about $1.10^{-10} \mathrm{~m} / \mathrm{s}$.

It is interesting to note that, by improving some of the measuring techniques and for longer testing stretches of the drift, one might even obtain permeability values on the order of $10^{-12} \mathrm{~m} / \mathrm{s}$, and this means that this type of largescale test could be used in the future as an acceptability test of individual waste storage drifts.

Besides the great specific interest of this determination, such large-scale tests provide extremely useful data as to the actual meaningfulness of borehole tests, that are more frequently a dopted and easier to carry out.

In this specific case, the average permeability finding $\left(10^{-13} \mathrm{~cm}^{2}\right)$ proves compatible with the results obtained from water injections in boreholes starting from the walls of the same test room (average value $8.9 \cdot 10^{-13} \mathrm{~cm}^{2}$ ). Keeping account of the different testing modalities of the two types of test (fluid injection in boreholes and fluid withdrawal in the adit), but the comparison stresses also the importance of the "scale-effect" on this measure.

The examination of existing fractures (coupled with the water absorption test in theboreholes) may finally allow to determine the fracture porosity of the rock mass, to which the transport of the radionuclides is linked.

Carlsson et al present the results of special hydraulic tests carried out within the framework of the same "Stripa Project"; the paper discusses the usefulness of the crosshole technique for defining the hydraulic parameters of the formation and for identifying the geometrical characteristics of a band of highly fractured material.
The hydraulic interference test was conducted after a buildup phase of over 3 months. The packed-off section in the first borehole was changed into a free-flowing state, with a continued pressure recording in the second borehole. The response showed a hydraulic interconnection between the two holes. It was possible on the basis of the hydraulic properties obtained, to evaluate the specific storage coefficient, and to indicate, in a preliminary way, the direction of the fractured zone.

The use of geophysical measurements ("mise à la masse method") was also used in order to locate the structure. The comparison of the permeability results obtained for the different test methods used is quite interesting. Such a comparison confirms the need not to restrict the investi. gation to a single method for measuring permeability, and the need to define the permeability characteristics of the rock mass on the basis of different tests which often complement each other.

The paper by Lee et al. refers about the investigations conducted to characterize the permeability of rock masses located in the Canadian Shield. Also in this case, different types of tests were carried out (at depths from $200 \mathrm{~m}$ down to over $1200 \mathrm{~m}$ ), basically according to three types of procedures: a) instantaneous withdrawal tests (slug tests, pulse tests, drill stem tests); b) instantaneous injection tests (slug tests and pulse test); c) constant pressure injection tests (step type).

The comparison among values obtained by the constant head tests, and by the transient tests, shows a ratio between the permeability values measured by the transient head, and the permeability values measured by the constant head which vary from 1.1 to 7.6 .

Furthermore, both in the "withdrawal" and in the "injection" cases, the "pulse" test provides permeability values which are much lower than in the "slag test".

It is also interesting to examine the decrease of permeability with depth; also in this case such a decrease is sharp for the first $200-250 \mathrm{~m}$ of depth (from $10^{-7} \mathrm{~m} / \mathrm{s}$ to $10^{-11}$ $\mathrm{m} / \mathrm{s}$ ), and it becomes less sizeable at greater depths. In the deep tests in granite with no fractures permeability values of $10^{-14} \mathrm{~m} / \mathrm{s}$ were measured, that is values at the extreme lower range of the field testing equipment used.

\section{Theoretical and general analyses for a better interpretation of the permeability tests}

It is well-known that the study of water flow inside fractured media may be conducted from a theoretical point of view by following two different approaches: in the first, the rock mass is considered as consisting of impermeable material divided by discontinuities more or less intercommunicating, and the water flow through these discontinuities is examined in detail; according to the second approach, the "impermeable rock-discontinuity" unit is replaced with a continuous medium, which is generally anisotropic and which on average has the same hydraulic characteristics. The latter method may be adopted when the rock mass may be taken as being homogeneous, that is when the spacing between the "hydraulically active" fractures is sufficiently close in relation to the scale of the problems to be studied. This schematization helps in dealing with water flow problems inside a rock mass, especialy because these problems can be tackled with numerical calculation methods.

In order to define an "equivalent permeability tensor", it is necessary that it be independent from the limit condi- 
tions imposed on the reference volume, that it be symmetric, and that it should tend to a limit value as the reference volume increases. This however, does not always occur at the scale of the in situ tests carried out in test boreholes. The paper presented by Feuga deals with this problem.

A particular test array was studied to evaluate the possibility of obtaining information on the permeability tensor of a fissured granite rock. It consists of injecting water into a borehole (with a double-packer unit) and then measuring the pressure rise in three holes drilled according to a tetrahedric pattern, so as to involve a rock mass of about $12 \mathrm{~m}^{3}$ (the fracturing density found for each borehole was on ave rage 3 fractures $/ \mathrm{m}$ ).

The test pointed out that in order to be able to consider the rock mass being investigated as equivalent to a porous medium, the borehole lengths, the lengths of the injection cell and of the pressure measurement cell, should have been greatly increased with the risk, however, of involving not only the level of diffused fractures, but also that of large discontinuities.

Indeed, it should be borne in mind that if different kinds of structures are present, the equivalent porous medium is to be defined for each of such different levels. The representative volume characterizing a fracture level should not include larger discontinuities.

It must also be recalled that the larger the volume investigated for determining the permeability, the greater the permeability value obtained. This depends on the fact that with larger volumes different levels of fracturing are involved, which are generally characterized by larger openings, and thus much higher the hydraulic conductivity.

A detailed and accurate "geostatistical" investigation of the fracturing of the rock mass is to be carried out before deciding on how the in situ permeability tests are to be conducted.

In the paper presented by Mironenko the processes occurring during the pumping tests and other permeability tests are discussed. The influence of the state of stress of the rock massif on the results of the permeability tests is pointed out, as well as the possibility of evaluating compressibility by experimental pumping tests, and the utilization of field water tests for evaluating the state of stress of rocks.

In particular, the possibility of monitoring the area where intense pumping is to occur so as to evaluate the deformability characteristics of the soils is discussed, as well as the possibility of measuring the state of stress by means of hydraulic fracturing techniques during mining operations, starting from holes with different orientations.

\section{Case histories and special in situ tests}

Well-documented case-histories illustrating special tests for the construction of engineering works are important for verifying the applicability of advanced research technologies, and for comparing experiences amongst technicians operating in this sector.

In the specific case of investigations for determining permeability, these verifications are very interesting in consideration of widely different methodologies used. Even a mere comparison of results obtained by different tests carried out for the same soils may yield some useful indications for advancing knowledge in this field.

For works involving important technological and economic decisions, permeability tests at a scale that allow to keep account of the complexity of the soils may not prove to be unwise. In this way, it would be possible to overcome the uncertainties of the design forecasts related to the evaluation of the permeability characteristics (trial embankments can be considered "at limit" large-scale in situ tests).

Sigismond and Doucerain report about an experimental largescale test for the design of the dewatering system of the excavations for the Nogent-sur-Seine nuclear power plant:

For the foundations, the water table had to be lowered about $3.5 \mathrm{~m}$, the environmental impact of such a measure was not to be too large and the amount of water removed not too high.

Four experimental curtain walls were built at depths from 14 to $26.50 \mathrm{~m}$, and the size in plant being $15 \times 20 \mathrm{~m}$. Pumping tests were carried out before and after the building of such curtain walls. An analysis of the result provided by the piezometers installed at various elevations inside and outside the wall allowed to determine the permeability of the various soil levels; an analysis of the water flow as a function of the depth of the watertight wall, allowed to make correct choices for the final construction.

An evaluation of the water flow to be removed during the works made on the basis of the findings of this test, was confirmed after the construction stage.

A type of test which in many respects is quite similar to that described is reported in the paper by Manfredini and Silvestri. In this case the permeability was to be determined not for dewatering purposes, but on the contrary to evaluate the losses there might be through the bottom of an artificial hydroelectric reservoir.

The heterogeneity of the deposit (and the large costs involved in an artificial lining of about $750.000 \mathrm{~m}^{3}$ ) suggested that large-scale permeability tests should be carried out. A vertical soil prism $5.2 \mathrm{~m}$ wide and $32 \mathrm{~m}$ deep, was hydraulically isolated by means of a concrete diaphragm wall. A steel cap was secured to the top and the gap between soil and cap was filled with water at a pre-established hydraulic head. The corresponding increase in pore pressure was measured in the soil and a flow analysis allowed a reasonable picture of soil permeability. In this case, as in the previous one it will turn out to be very useful for future developments to make a thorough review of all the permeability routine tests carried out and compare, where possible the forecasts that would have been made on the basis of these elements with the findings of the large-scale permeability tests.

In their papers, Haq and Hashmi refer about a broad series of "in borehole" permeability tests (essentially Lugeon test) conducted for characterizing the foundation rock of the Simly Dam. Preliminary tests showed large water leakage along the first $20-25 \mathrm{~m}$, and so an elaborate investigation grouting programme was carried out.

As in many valleys, as a consequence of different states of stress, higher permeability values are found at the two abutments, whilst smaller values are obtained along the bed.

Permeability tests were extremely useful in determining design criteria for the grout curtain, the depth, the spacing, the inclination and the injection pressure of the grout holes.

The paper by Loudière and Fatton is the only one of the Session that deals with the permeability of very superficial soils (from 1 to 3 metres). In particular, a series of tests for characterizing the soils at the bottom of lagoons or shallow artificial ponds were carried out according to the "Porchet" method, which consists in measuring as a function of time, the rate of water flow into a shallow hole. 
Causes for possible mistakes inherent in the measurements are discussed and suggestions are made to avoid such errors.

Finally, a series of experimental findings referring to different soils are shown. The comparison with laboratory tests shows that the latter generally provide lower permeability values. It is very likely that these may be due, beside the factors mentioned by the Authors, to the in situ effect of a meaningful "structure" and to some permeability anisotropy of the soil.

The paper by Krupoderov describes the results of a series of in situ investigations on debris resistance to washing out on natural slopes at various flow rates.

The influence of the grain-size of the soils, of the density, of the water content on debris resistance to wash out are also examined.

This topic is borderline in terms of the determination of in situ permeability, but it is important for predicting the development of erosional and mudflow processes in mountain and hilly regions.

\section{Final remarks and points for further discussion}

Some general comments are to be made at the conclusion of this review.

As in many other fields of soil and rock mechanics, there is a growth of interest in the development of new techniques and new methods for the determination of permeability by means of in situ tests.

The main developments in this area may be summarized as follows:

\section{Rock mass permeability}

The drawbacks and the limits of the pack tests are well recognized: it is therefore important that technological measures aiming at limiting the uncertainties of the tests be adopted also for routine tests. In relation to this, the possibilities offered by the wide range of currently available instrumentation do not appear to be fully exploited.

Permeability tests, typical of oil prospection are being applied successfully with appropriate changes in the area of rock mechanics. On the basis of this example it appears to be quite important for geotechnical researchers to use in the future, to a much greater extent than has been done so far, the experience of technicians working in other fileds (oil prospection and oil production, mining, irrigation and agricultural research and so on).

The "harmonic probe" may prove to be very useful in measuring the transmissivity of individual fractures; this may be taken as a typical example of a joint application of modern measurement techniques and of calculation methods for interpreting the tests.

A valid aid in interpreting permeability test results for rock masses is provided by fracturing surveys which are now carried out on a routine basis, by means of borehole television cameras, with continuous data registration, or by impression packers in some particular stretches.

\section{Soil permeability}

The most promising results have been obtained by using pressuremeters or self-boring permeameters which do not excessively disturb the soil. A more extensive use of such equipment, also for routine tests will undoubtedly lead to a meaningful improvement in the design forecasts of the behaviour of engineering structures.
Some points may deserve further discussion, for instance: - In situ measurement of the permeability of soils and rocks as a function of the variation of the state of stress induced by the engineering structure;

- Meaningfulness of the different "in borehole" tests in defining the permeability of large rock volumes;

- Meaningfulness and limits of the "in borehole" tests for defining an "equivalent porous medium" for a rock mass; - Possible improvements in test methods and in the way they are carried out so as to make pressuremeter of selfboring permeameter tests more meaningful from the "scale" standpoint in relation to the macrostructure of the soils;

- Possible future innovations in self-boring instruments or in operation modalities, to evaluate also the vertical permeability of soils.

\section{Acknowledgements}

This study was supported by a C.N.R. Research Contract (Working Group on Rock Mechanics at the University of Rome).

\section{References}

BAGUELIN F., JEZEQUEL J.F., LE MEHAUTE A. (1974): Self boring placement method of soil characteristics measurements. Proc. Eng. Found. Conf. on subsurface exploration. Henniker. New Hampshire.

BERNAIX J: (1969): New laboratory methods of studying the mechanical properties of rocks. Int. J. Rock Mech. Min. Sci., 6.

BJERRUM L., NASH J.K.T.L., KENNARD R.M., GIBSON R.E. (1972): Hydraulic fracturing in field permeability testing. Geotechnique, 22, No. 2.

BONALDI P., MANFREDINI G., MARTINETTI S., RIBACCHI R. SILVESTRI T. (1983): Foundation rock behaviour of the Passante dam (Italy). V Int. Conf. ISRM. Melbourne.

BRACE W.F. (1980): Permeability of crystalline and argillaceous rocks. Int. J. Rock Mech. Min. Sci., 17.

BURGHIGNOLI A. CALABRESI G. (1967): A large sampler for the evaluation of soft clays behaviour. Spec. Sess., Proc. IX ICSMFE. Tokyo.

CAPOZZA F. (1977): Panel discussion on Session 3. Int. Symp. on the Geotechnics of structurally complex formations. Capri.

CLARKE B.G., CARTER J.P., WROTH C.P. (1979): In situ determination of the consolidation characteristics of saturated clays. Design parameters in Geotechnical Engineering, 2. Proc. VII ECSMFE. Brighton (U.K.)

COLOMBO P. (1973): Discussion on theme 2. Effetti meccanici del moto dell'acqua nelle rocce sciolte e lapidee. XI Convegno Italiano di Geotecnica. Milano.

CROCE A. (1973): Discussion on theme 2. Effetti meccanici del moto dell'acqua nelle rocce sciolte e lapide. XI Convegno Italiano di Geotecnica. Milano.

DAVIS S.N., TURK L.S. (1964): Optimum depth of wells in crystalline rocks. Groundwater, 2, No. 2 .

FRANKLIN J.A. (1979): General report. Use of tests and monitoring in the design and construction of rock structures. IV Int. Conf. ISRM. Montreux.

GIBSON R.E. (1970): An extension to the theory of the constanthead in situ permeability test. Geotechnique, 20, No. 2.

HAMSON B.C. (1978): The hydrofracturing stress measuring method and recent field results. Int. J. Rock Mech. Min. Sci., 15 . 
HEITFELD K.H., KRAPP L. (1981): The problem of water permeability in dam geology. Bull. IAEG, 23.

IAEG Int. Ass. Eng. Geol, (1981): Report of the Commission on site investigations.

JAMIOLKOWSKI M., LANCELLOTTA R., PASQUALINI E., MARCHETTI S., NOVA R. (1979): General report. Design parameters for soft clays. VII ECSMFE' Brighton (U.K.).

JOUANNA P. (1972): Essais in situ de percolation sous contrainte. Proc. Int. Symp. Percolation through fissured rock. Stuttgart.

LOUIS C. (1981): General report on Session 3. Eau souterraine et problèmes d'infiltration. Proc. X ICSMFE. Stockholm.

LOUIS C, PERROT M. (1972): Analyse tridimensionnelle des écoulements dans le massif de fondation du barrage de Grand Maison. Proc. Int. Symp. on Percolation through fissured rock. Stuttgart.

MAINI Y.N.R., NOORISHAD J,, SHARP J. (1972): Theoretical and field considerations on the determination of in situ hydraulic parameters in fractured rock. Proc. Int. Symp. Percolation through fissured rock. Stuttgart.

MANFREDINI G., MARTINETTI S., RIBACCHI R. (1975): Mutual influence of water flow and state of stress in the analysis of dam foundations. Proc. Symp. Criteria and assumptions for numerical analysis of dams. Swansea.

MASSARSCH K.R. (1978): New aspects of soil fracturing in clay, Proc, ASCE, 104, No, GT8.

MIEUSSENS C., DUCASSE P. (1977): Mesure en place des coefficients de permeabilité et des coefficients de consolidation horizontaux et verticaux. Revue Canadienne de Geotechnique, 14 .

MIYABE N. (1969): Directions of research on land subsidence. Proc. of the Symposium on Land Subsidence.

MOORE P.T., BALBIS R.E. (1979): Head losses in packer tests, Proc. ASCE, 105, No. GT9.

MORGENSTERN N.R., GUTHER H. (1972): Seepage into an excavation in a medium possessing stress-dependent per- meability. Proc. Int. Symp. on Percolation through fissured rock. Stuttgart.

PEARSON R., MONEY M.S. (1977): Improvements in the Lugeon or packer permeability test. Q.J. Eng. Geol., 10.

POLAND J.F. (1969): Status of present knowledge and needs for additional research on compaction of aquifer systems. Proc. of the Symposium on Land Subsidence.

RAVEN K.G., GALE J.E. (1977): Subsurface containment of solid radioactive waste: A study of the surface and subsurface structural and groundwater conditions at selected underground mines and excavations. Internal report, Library of Geological Survey of Canada.

RIETSEMA R.A., VIERGEVER M.A. (1979): In situ measurement of permeability. Proc. VII ECSMFE. Brighton (U.K.).

ROSEGREN K.J., JAEGER J.C. (1968): The mechanical properties of an interlocked low-porosity aggregate. Geotechnique, 18.

SNOW D.T. (1968): Rock fracture spacings, openings and porosities. J. Soil Mech. Found. Div., Proc. ASCE, 94.

TELLAM J.H., LLOYD J.W. (1981): A review of the hydrogeology of British onshore non-carbonate mudrocks. Q.J. Eng. Geol.

U.S. Department of the Interior. Bureau of reclamation (1977) Grand Water Manual.

URIEL ROMERO S., AOIZ L.U. (1981): Coastal soils permeability based on tidal damping. Proc. X ICSMFE. Stockholm.

WILKES P.F, (1974): Permeability tests in alluvial deposits and the determination of $\mathrm{K}_{0}$. Geotechnique, 24, No. 1 .

WILKINSON W.B. (1968): Constant head in situ permeability tests in clay strata. Geotechnique, 18.

WITHERSPOON P.A., GALE J.E., COOK N.G.W. (1977): Radioactive waste storage in argillaceous and crystalline rock masses. I Int. Symp. on Storage in ewcavated rock caverns. Rockstore, 77. Stockholm. 